\title{
State and transition modeling: An ecological process approach
}

\author{
TAMZEN K. STRINGHAM, WILLIAM C. KRUEGER, AND PATRICK L. SHAVER
}

Authors are assistant professor and professor, Department of Rangeland Resources, Oregon State University, Corvallis, Ore. 97331; and rangeland management specialist, USDA, Natural Resources Conservation Service, Grazing Land Technology Institute, Corvallis, Ore. 97331.

\begin{abstract}
State-and-transition models hold great potential to aid in understanding rangeland ecosystems' response to natural and/or management-induced disturbances by providing a framework for organizing current understanding of potential ecosystem dynamics. Many conceptual state-and-transition models have been developed, however, the ecological interpretation of the model's primary components, states, transitions, and thresholds, has varied due to a lack of universally accepted definitions. The lack of consistency in definitions has led to confusion and criticism indicating the need for further development and refinement of the theory and associated models. We present an extensive review of current literature and conceptual models and point out the inconsistencies in the application of nonequilibrium ecology concepts. The importance of ecosystem stability as defined by the resistance and resilience of plant communities to disturbance is discussed as an important concept relative to state-and-transition modeling. Finally, we propose a set of concise definitions for state-and-transition model components and we present a conceptual model of state/transition/threshold relationships that are determined by the resilience and resistance of the ecosystems' primary ecological processes. This model provides a framework for development of process-based state-and-transition models for management and research.
\end{abstract}

Key Words: state, transition, threshold, modeling, ecological, process

Applied ecology disciplines, such as range management, are necessarily organized around a response model based on theoretical supposition. Thus, the litmus test for an ecological or mechanistic model is its ability to predict the consequences of natural disturbances and/or management activities with acceptable precision over timescales relevant to management. Traditional theories of plant succession leading to a single climax community have been found to be inadequate for understanding the complex successional pathways of semi-arid and arid rangeland ecosystems considering timescales important for making management adjustments (West 1979, Westoby 1980, Anderson 1986, Foran et al.

Authors wish to thank L.E. Eddleman, N.E. West, M. Westoby, W.A. Laycock, and G.L. Peacock for insightful review.

This article is submitted as Technical Paper No. 11874 Oregon Agricultural Experiment Station, Corvallis, Ore.

Manuscript accepted 8 Oct. 2002.

\section{Resumen}

Los modelos de estados-y- transición presentan un gran potencial para ayudar a entender la respuesta de los ecosistemas de pastizal a los disturbios naturales y/o inducidos por el manejo al proveer una estructura para organizar el conocimiento presente de las dinámicas del potencial del ecosistema. Muchos modelos conceptuales de estados-y-transición han sido desarrollados, sin embargo, la interpretación ecológica de los componentes principales del modelo: estados, transiciones y umbrales han variado debido a la carencia de definiciones universalmente aceptadas. La falta de consistencia en las definiciones ha conducido a confusión y critica indicando la necesidad de un mayor desarrollo y refinamiento de la teoría y los modelos asociados. Nosotros presentamos una revisión extensiva de la literatura actual y modelos conceptuales y puntualizamos las inconsistencias en la aplicación de los conceptos de la ecología de no equilibrio. La importancia de la estabilidad del ecosistema, definida como la resistencia y resilencia de las comunidades vegetales a los disturbios, se discute como un concepto importante relativo al modelaje de estados-y- transición. Finalmente, proponemos un grupo de definiciones concisas para los componentes del modelo de estados-y-transición y presentamos un modelo conceptual de las relaciones de estados/transiciones/umbrales que están determinadas por la resilensia y resistencia de los principales procesos ecológicos del ecosistema. Este modelo provee un marco para el desarrollo de modelos de estados-y-transición basados en procesos para manejo e investigación.

1986, Tausch et al. 1993). After 50 years of applying the quantitative climax model of Dyksterhuis (1949) to rangeland management its predictive capabilities have come under scrutiny. The inability of the model to incorporate multiple pathways of change has led some ecologists to abandon the model completely (Wilson 1984, Smith 1988). The recognition of this inadequacy has generated a search for an alternative theory that more correctly reflects the observed dynamics of rangeland ecosystems. As many scientists were questioning the validity of the climax model, Westoby et al. (1989) developed a foundational discussion and conceptual model based on non-equilibrium ecology. Numerous scientists have utilized these concepts as a basis for the development of conceptual models of vegetation dynamics which incorporate multiple successional pathways, multiple 
steady states, thresholds of change, and discontinuous and irreversible transitions (Archer 1989, Friedel 1991, Laycock 1991, Fuhlendorf et al. 1996, Stringham 1996, Rietkerk and Van de Koppel 1997, Davenport et al. 1998, Oliva et al. 1998, Petraitis and Latham 1999, Plant et al. 1999, West 1999, West and Young 2000, Stringham et al. 2001). However, the ecological interpretation of Westoby's model has varied due to a lack of universally accepted definitions of the key concepts. The lack of consistency in definitions has led to confusion and criticism indicating the need for further development and refinement of the theory and associated models (Iglesias and Kothmann 1997).

The USDA Natural Resources Conservation Service (NRCS) adopted the use of state-and-transition vegetation dynamics in describing rangeland ecological sites. The attempt to use this concept illustrated the inconsistency in the definitions and concepts. The NRCS recognizes the need for consistency in the application of the concepts (USDA 1997). For management to utilize the non-equilibrium ecological model the definitions of model objects must be succinctly stated and validated.

\section{Background}

Westoby et al. (1989) was the first to apply the use of state-and-transition terminology to non-equilibrium theory for the purpose of producing a management focused model that describes vegetation dynamics in a non-linear framework as an alternative to the linear continuum process incorporated in the quantitative climax model. The authors defined a "state" as an alternative, persistent vegetation community that is not simply reversible in the linear successional framework. We interpret Westoby's transitions as trajectories between states with the characteristic of the transition being either transient or persisting. Transitions between states are often triggered by multiple disturbances including natural events (e.g., climatic events or fire) and/or management actions (grazing, farming, burning, etc.). Transitions may occur quickly, as in the case of catastrophic events like fire or flood or slowly over an extended period of time as in the case of a gradual shift in weather patterns or repeated stresses like frequent fire. Regardless of the rate of

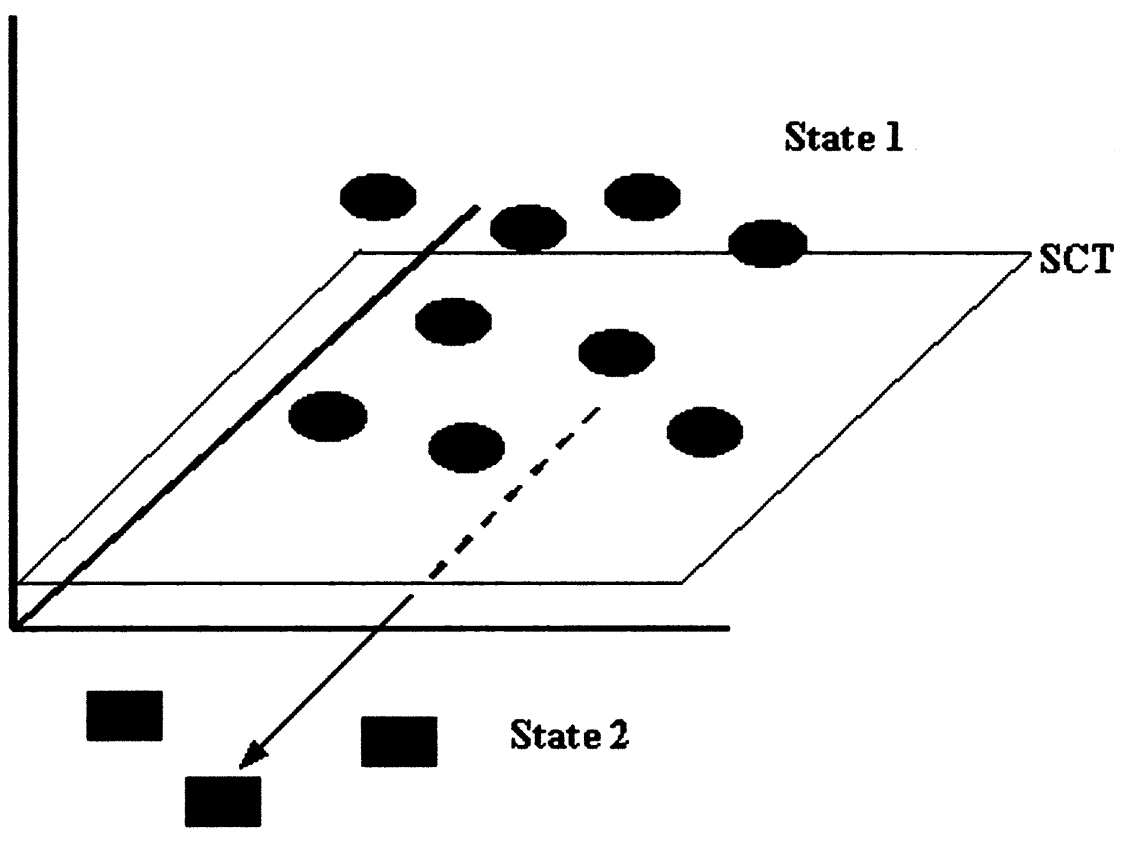

Fig. 1. Broad applications of the state-and transition concepts. Derived from the Society for Range Management, Task Group on Unity in Concepts and Terminology (1995). The plane labeled SCT (site conservation threshold) represents a change from 1 ecological site to another and may also be considered a threshold between 2 states. The individual boxes or ovals represent plant communities or seral stages that exist within 1 site.

change the system does not stabilize until the transition is complete.

Quantitative approaches to ecological thresholds have been presented by May (1977), Wissel (1984) and Rietkerk and van de Koppel (1997). Archer (1989) introduced the qualitative concept of a transitional threshold. He modeled the expansion of a woodland community into a grassland domain using a transitional threshold as the boundary between the respective grassland and shrub domains. Whisenant (1999) proposed a model of degradation based on the stepwise degradation concept of Milton et al. (1994). Whisenants model is similar to Archer's, which incorporates 2 transition thresholds, the first being controlled by biotic interactions and the second by abiotic limitations. The concept of a transitional threshold as used by both Archer and Whisenant is similar to the persistent transition as the successional processes shift from grass controlled to shrub controlled, however, in Whisenant's (1999) model the focus is on ecological processes not vegetative groups. Friedel (1991) focused on the concept of thresholds of environmental change between domains of relative stability. She defined a threshold as a boundary in space and time between 2 domains or states, which is not reversible on a practical time scale without substantial inputs of energy.
As defined, Friedel's thresholds mirror Westoby et al.'s (1989) definition of persistent or irreversible transitions. However, the use of thresholds in current state-andtransition models has not been consistent nor clear on whether thresholds exist between all states or only a subset of states.

Conceptual models, based on these ideas, have incorporated states and transitions but not always thresholds. As a result, there have been both a broad interpretation of states, more or less separated by thresholds, and a narrow interpretation of states that approximate seral stages or phases of vegetation development. Broadly applied, states are climate/soil/vegetation domains that encompass a large amount of variation in species composition. Specifically a grassland state would include many seral stages of the overall grassland community. These seral stages are within the amplitude of natural variability characteristic of the state and represent responses to disturbances that do not force a threshold breach. Westoby et al. (1989), Archer (1989), and Archer and Smeins (1991) provided examples of this broad definition of state where domination of successional processes determine the boundary of the state (e.g. grass controlled succession versus shrub controlled succession). The Society for Range Management, Task Group on Unity in Concepts 
and Terminology (1995) developed a graphical depiction of the broad application of states with multiple vegetative stages diagrammed within one state (Fig. 1). Milton et al. (1994) and Whisenant (1999) de-emphasized the species component of the ecosystem within their models, focusing instead on the functional integrity and self-repair thresholds of the site for determining state boundaries. In the broad definition of state the natural variability characteristic of plant communities within a site is the result of, and contributes to, the current functional integrity of the site's primary ecological processes (hydrology, nutrient cycling, and energy capture).

The narrower interpretation of state allows for far less variation in plant community composition. States are typically depicted as seral stages or phases of vegetation development. In the narrow application of the model a state change does not necessarily represent a movement across a threshold as envisioned by Friedel (1991). Figure 2 represents the narrow interpretation of states as adapted from West (1999). Boxes represent states and arrows indicate the transitions between states. Note that many of the transitions are reversible, however, the threshold indicates a persistent transition. Other examples of specific or narrow applications of states are presented by Weixelman et al. (1997), Oliva et al. (1998), Allen-Diaz and Bartolome (1998), West (1999), and West and Young (2000). The specific approach to state-andtransition modeling may be the reason for statements that such models are structurally similar to traditional linear climax-seral stage models. The significant difference being the description of communities as discrete entities as opposed to the continuum concept of the quantitative climax model (Iglesias and Kothmann 1997).

\section{Ecological Resistance and Resilience}

The concept of stability as defined by the resistance and resilience of plant communities have been discussed in the literature for sometime and offer important insights for state-and-transition models (Margalef 1969, Verhoff and Smith 1971, Holling 1973, May 1977, Noy-Meir and Walker 1986). Resistance is defined as the ability of the system to remain the same while external conditions change whereas resilience is the ability of the system to

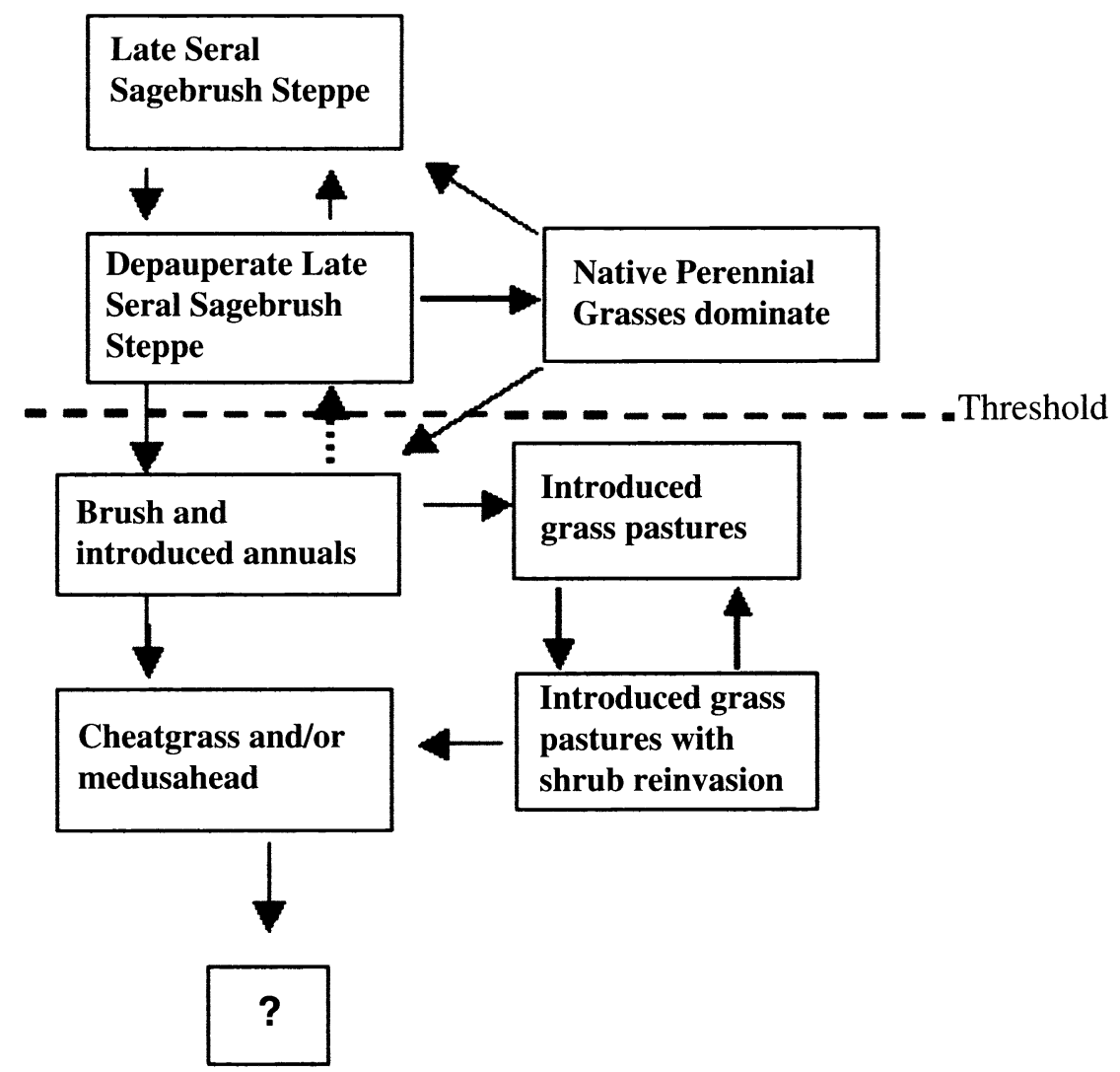

Fig. 2. Specific, or narrow, application of states with each state (box) representing 1 phase or seral stage of vegetation development. Transitions between states are indicated by arrows and the dashed line represents a threshold. The dashed transitional line signifies the requirement of substantial energy input to move the state back across the threshold. Modified from West (1999) and West and Young (2000).

recover after it has been disturbed. Thus, fully functioning ecosystems are both resistant to change and resilient or able to recover without external energy inputs thereby maintaining stability while allowing for fluctuating combinations of plant species over time. States, by definition are relatively stable (Westoby et al. 1989), therefore it follows that a state change is only possible when a threshold is crossed. Accepting this concept points out the confusion that is apparent in the current attempts to produce state-and-transition models. The specific or narrow approach has produced models, which depict state changes occurring without having crossed a threshold. Often such changes are diagrammed as reversible and perhaps occur without the input of management resources (Fig. 2). Rather than consider these vegetation dynamics as state changes it is more appropriate to consider them as phase shifts or plant community dynamics within a state. Therefore, within a state there exists the potential for a large variation in species composition, which is merely a reflection of plant community dynamics. A state change, on the other hand, requires a shift across a boundary or threshold, defined by a change in the integrity of the site's primary ecological processes, resulting in a different potential set of plant communities.

\section{Rangeland Ecological Processes}

Ecological processes functioning within a normal range of variation will support a suite of specific plant communities. The important primary processes are (1) hydrology (the capture, storage, and redistribution of precipitation); (2) energy capture (conversion of sunlight to plant and animal matter); and (3) nutrient cycling (the cycle of nutrients through the physical and biotic components of the environment (Pellant et al. 2000, Whisenant 1999). Pellant et al. (2000) defines the functioning of an ecosystem by "the degree to which the integrity of the soil, vegetation, water, and air, as well as the ecological processes of the rangeland ecosystem, are 
balanced and sustained". Integrity is defined as the "maintenance of the functional attributes characteristic of a locale, including normal variability" (Pellant et al. 2000). Degradation of an ecosystem occurs when the integrity of the system is damaged or lost. Maintenance of a functional site or repair of a damaged site requires management focused on soil stability, nutrient cycling, and the capture, storage and safe release of precipitation. Vegetation goals should be based on the concept of vegetation as a tool for maintaining or repairing damaged ecological processes rather than predefined species groups. Monitoring of species groups may be a mechanism for evaluating or detecting change in the site's ecological processes.

\section{Clarification of the Concepts and Definitions}

\section{Spatial Scale}

Ecosystems are difficult to define or delimit in space and time. Hierarchy theory, as applied to ecological systems, suggests several levels of organization exist, i.e., organisms, populations, communities, ecosystems, landscapes (Archer and Smeins 1991). Each level of organization encompasses one or more of the primary ecological processes that are operating at specific spatial and temporal scales. Although landscape scale management may be the goal, our current understanding of organization function declines with increasing spatial and temporal scale.

The ecological site concept has long been utilized as an organization level that provides an appropriate spatial scale for inventory, evaluation, and management of rangelands (USDA 1997). Organisms, populations, and communities exist within this spatial scale and interact with one another through the flow of water and energy, and the cycling of nutrients. An ecological site has evolved a kind of characteristic plant community such as cool season shrub-grass or warm season grassland. Within an ecological site numerous expressions of the various developmental stages of the characteristic plant community can occur. The concept and definition of an ecological site fits the large-scale interpretation of the state-and-transition model. We define the ecological site as the minimum scale for definition of a state.

\section{Temporal Scale}

The definition of threshold as presented by Friedel (1991) indicates that once a threshold has been breached return to the previous state is precluded within a time frame relevant to management, without substantial inputs of energy. Ecological management models should focus on the time required to repair damaged ecological processes not on a time scale predicated by management. Careful consideration of the threshold concept negates the need for including management timescales in the definition of ecological thresholds as these thresholds represent a permanent change in the function of the state. Thus, restating the threshold definition, independent of management timescales, results in the conclusion that once a threshold has been violated return to the prior state is precluded without substantial inputs of energy. Therefore, under the current climatic conditions and without substantial inputs of energy, state changes are permanent. The temporal scale is defined by the permanence of the current climate regime.

\section{State}

A state is a recognizable, resistant and resilient complex of 2 components, the soil base and the vegetation structure. The vegetation and soil components are necessarily connected through integrated ecological processes that interact to produce a sustained equilibrium that is expressed by a specific suite of vegetative communities.

\section{Soil Base and Vegetation Structure}

The base of any rangeland ecosystem is the soil resource that has developed through time from a specific parent material, climate, landscape position, and interaction with soil and terrestrial biota. These factors are the primary determinants of the ecological site's capability. The integrity of the soil resource, as reflected by site hydrology and nutrient cycling, is directly connected to the composition and energy capture process of the above-ground vegetative component. The interaction between the soil resource and the associated vegetative community determines the functional status of the state's ecological processes.

- Soil Base: a component that results from the interaction of climate, abiotic soil characteristics, soil biota and topography that determines the hydrologic characteristic and biotic potential of the system
- Vegetation Structure: a component resulting from above ground communities of living organisms, whose vital attributes (Noble and Slatyer 1980) competitively capture and utilize the system's available energy, water, nutrients, and space.

The interaction between the structural attributes of soil and the vegetative communities, through the processes of energy capture, hydrology and nutrient cycling defines the resilience and resistance of the state.

\section{Resilience and Resistance}

The stability of a state is defined above in terms of resilience and resistance. Resilience and resistance are inherent properties of an ecosystem that are determined by the physical components of the system and the functional capacity of the associated ecological processes. Resilience focuses on how far a system can be displaced from equilibrium before return to equilibrium is precluded. The emphasis is placed on the persistence of relationships as they affect the systems ability to adapt to change (Walker et al. 1981), therefore, resilience relates to the functioning of the system's ecological processes. Resistance indicates the ability of a system to remain at or near its equilibrium condition by maintaining control of its ecological processes. Thus, the strength of this control determines a system's inherent resistance to change. Consequently, under an existing climate, stability of a state is a function of the combination of its inherent resilience and resistance.

\section{Thresholds and Transitions}

Thresholds are points in space and time at which one or more of the primary ecological processes responsible for maintaining the sustained equilibrium of the state degrades beyond the point of self-repair. These processes must be actively restored before the return to the previous state is possible. In the absence of active restoration a new state, which supports a different suite of plant communities and a new threshold, is formed

- Thresholds: boundary in space and time between any and all states, or along irreversible transitions, such that one or more of the primary ecological processes has been irreversibly changed and must be actively restored before return to a previous state is possible.

Transitions are trajectories of change that are precipitated by natural events 
and/or management actions which degrade the integrity of 1 or more of the states primary ecological processes. Transitions are often composed of 2 separate properties that are defined by the state threshold. The first property is reversibility and it occurs within the state. The second property is irreversibility and it occurs once a threshold has been breached. Transitions are vectors of system change that will lead to a new state without removal of the stressor(s). The primary difference between the reversible and irreversible property of a transition is defined by the systems' ability or inability to repair itself.

- Transition: a trajectory of system change away from the current stable state that is triggered by natural events, management actions, or both.

- Reversible Property of the Transition: trajectory of change that occurs within a state and indicates the system is moving toward a threshold. Reversal requires elimination of the stress or stresses responsible for triggering the transition.

- Irreversible Property of the Transition: trajectory of change that occurs after a threshold has been breached. The system can no longer self-repair even with removal of the stressor(s). The system will not come to rest until a new equilibrium (i.e., new state) is established that supports a different suite of plant communities.

\section{Model Structure}

The conceptual model, illustrating the above definitions, is represented in Figures 3 and 4 . The model accommodates both the quantitative climax approach and the narrow application of the non-equilibrium approach to states and transitions (Fig. 5). States are diagrammed as the large boxes and are bordered by thresholds. Thresholds are the boundaries of any and all states, but may also occur during the transition between states. For a state change to occur a threshold must be breached. The small boxes within the state are referred to as plant community phases or seral stages and are joined by community pathways that flow in both directions. Transitions are reserved for a trajectory of change with the dashed line inside the state indicating the portion of the transition that is reversible with minimal input from management. Figure 4 illustrates the process of a state change. Once the threshold is crossed the state has lost control of its primary ecological processes, is no longer able to self-repair and will transition to a new equilibrium with a different ecological capability. The entire trajectory from a vegetation phase in State 1, across the threshold to the formation of State 2 is considered a transition and represents a degradation of ecological capability. The portion of the transition contained within the boundary of State 1 is reversible with removal of the stressor(s), however, once the trajectory crosses the threshold it is not reversible without active restoration including substantial energy input. Additional thresholds may occur while the system is in transition, changing the direction of the trajectory away from State 2 towards State 3 (Fig. 4). State-and-transition modeling efforts indicate the first threshold is forced by a change in the biotic component of the system whereas additional thresholds would involve changes in the soil resource (Westoby et al. 1989,
Milton et al. 1994, and Whisenant 1999).

Plant community phase changes within states, in addition to transitions of change, thresholds and multiple stable states are illustrated in Figure 5. The management and natural mechanisms responsible for community phase shifts and transition initiation must be defined in terms of ecological processes and included in the model description. For example, prolonged drought or overgrazing leads to a reduction in the perennial herbaceous understory. The decrease in perennial understory leads to a decrease in total energy capture and nutrient cycling. In addition, the plant community's ability to protect the soil from raindrop impact and potential soil erosion declines. The mechanism (or mechanisms) of disturbance have led to a change in the 3 primary ecological processes and a phase shift as diagrammed by community phase pathway P1 (Fig. 5). In the case of prolonged drought return to the late seral sagebrush steppe phase would gradually occur with a return to a normal or above normal precipitation period (P2). Increased available moisture leads to an increase in biomass of the herbaceous understory that translates into an increase in energy capture, nutrient cycling and an improvement in soil protection and site hydrology. The degradation mechanism of overgrazing would need to be addressed through grazing management with the goal of improving the function level of the primary ecological processes. Continued overgrazing would further decrease the vigor of the native herbaceous understory and further impact the community's ability to maintain control of the primary ecological processes. As the vigor of the native

\section{Objects within a State}

\section{$\ldots$ Reversible transition}

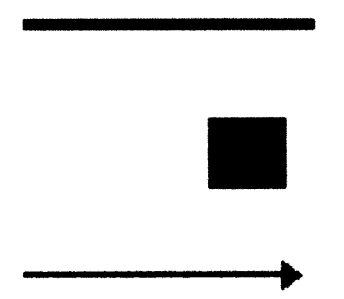

Threshold of the state

Plant community phases or seral stages within a state

Community pathways

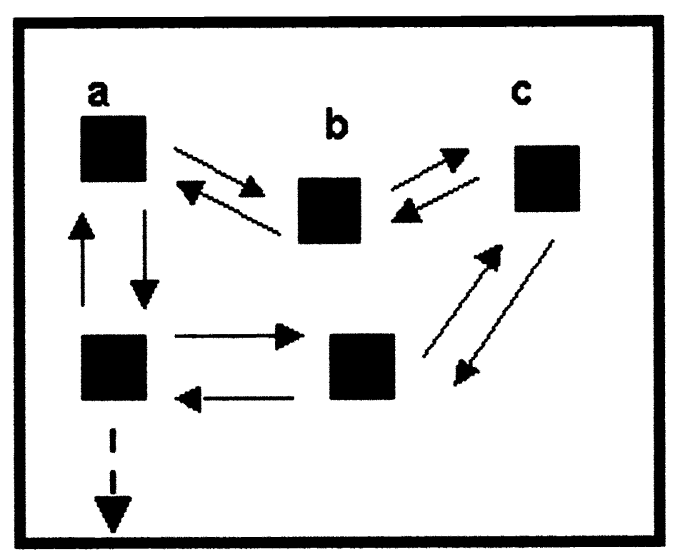

Fig. 3. Conceptual model depicting the objects of 1 state. Note the linear response, retrogression-succession model may be modeled within the state (i.e., a to $b$ to $c$ and vice-versa). 


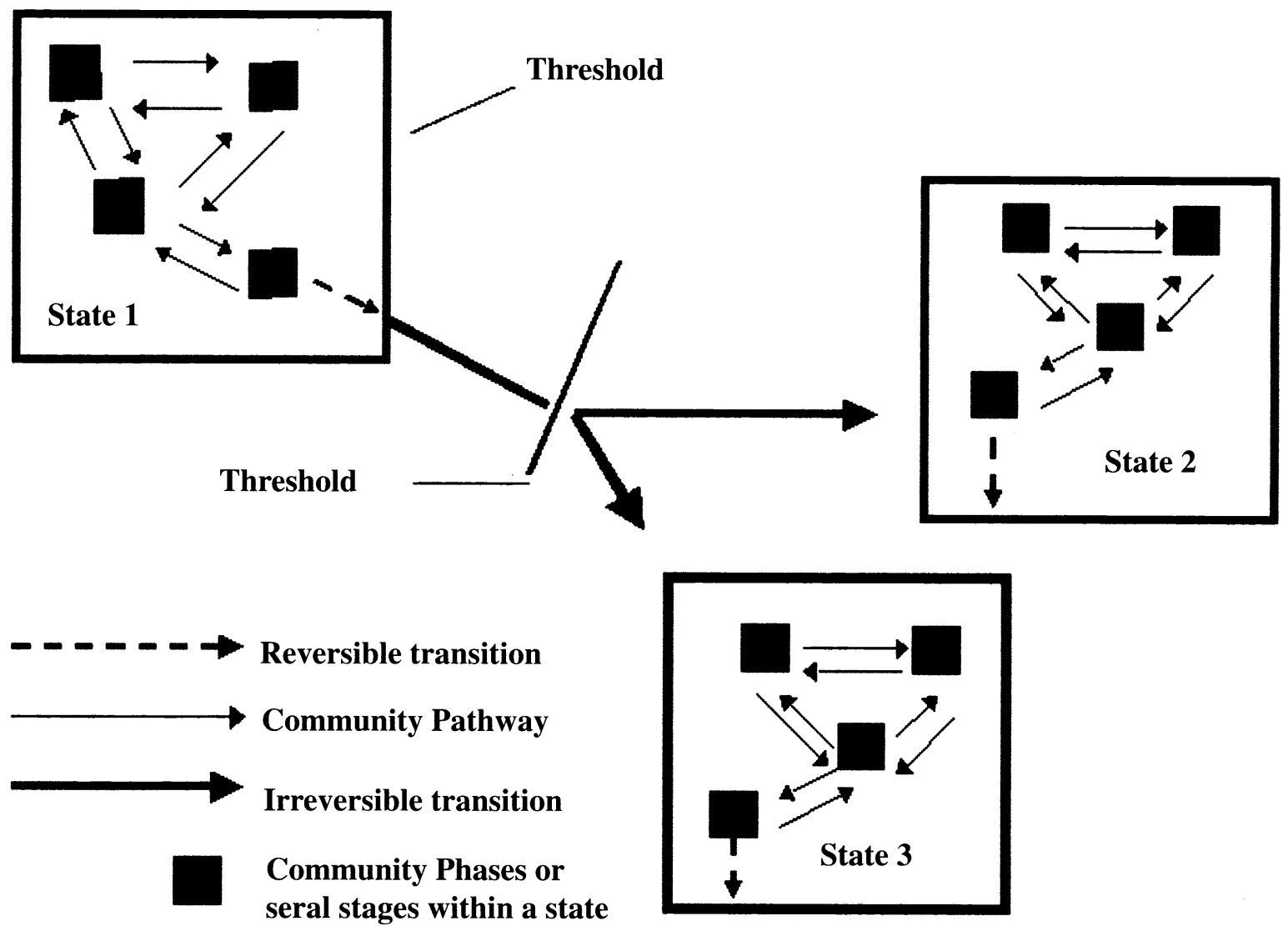

Fig. 4. Conceptual state-transition model incorporating the concepts of community pathways between plant community phases within states, reversible transitions, multiple thresholds, irreversible transitions, multiple pathways of change, and multiple steady states.

herbaceous community declines, the site is opened up for invasion by annual species. The transition from State 1 towards State 2 has begun and will continue without the removal of the stress from improper grazing (T1a). At the point in time where annuals dominate the herbaceous understory and fire frequency intensifies, the state has crossed a threshold and is transitioning to a new state (T1b). During this transition phase the plant community may still retain a minor component of sagebrush; however, this is not representative of a stable state and with increased fire frequency the brush will be eliminated and the new equilibrium state formed. The new state is defined as a Bromus tectorum (cheatgrass) and/or Taeniatherum asperum (medusahead) dominated community with a fire frequency interval of 2 to 3 years. Energy capture has declined and the time period for energy capture has been reduced. Nutrient cycling in both the vertical and horizontal plane has decreased with the shift to a shallow rooted, primarily monoculture community. The hydrology of the site will be impacted through a reduction in the amount of organic material being added to the soil and an increase in the potential for damage to soil surface structure from raindrop impact. Return to State 1 would be impossible without the use of intensive management inputs. The practicality of this level of management would preclude its use. State 3 may be the practical state of choice.

Although many scientists have recognized the short-comings of the quantitative climax model developed by Dyksterhuis (1949) there are ecosystems, generally of more mesic climates, where the linear model is appropriate. It is important to realize that any modeling approach is a best-fit solution, not a perfect-fit solution. Therefore, the retrogression-succession continuum can be modeled within the states to depict the situation where plant community phases do respond linearly. However, it is also possible for linear response mechanisms to be pushed past an ecological threshold, resulting in a state change.

\section{Conclusions}

Definitions and model concepts as discussed in this paper are being adopted by the USDA Natural Resources Conservation Service as the standard for describing vegetation dynamics in rangeland ecological site descriptions. State-and-transition models hold great potential to aid in understanding rangeland ecosystems' response to natural and/or managementinduced disturbances by providing a framework for organizing understanding of potential ecosystem dynamics. Many state-and-transition model applications are available in the literature, although the scale of interpretation of the concepts has varied. We have attempted to review and clarify a large amount of information into a proposed conceptual model of state/transition/threshold relationships that are determined by the resilience and resistance of the systems' primary ecological processes. Most of the components presented are not new; however, the proposed model attempts to clarify the definitions 


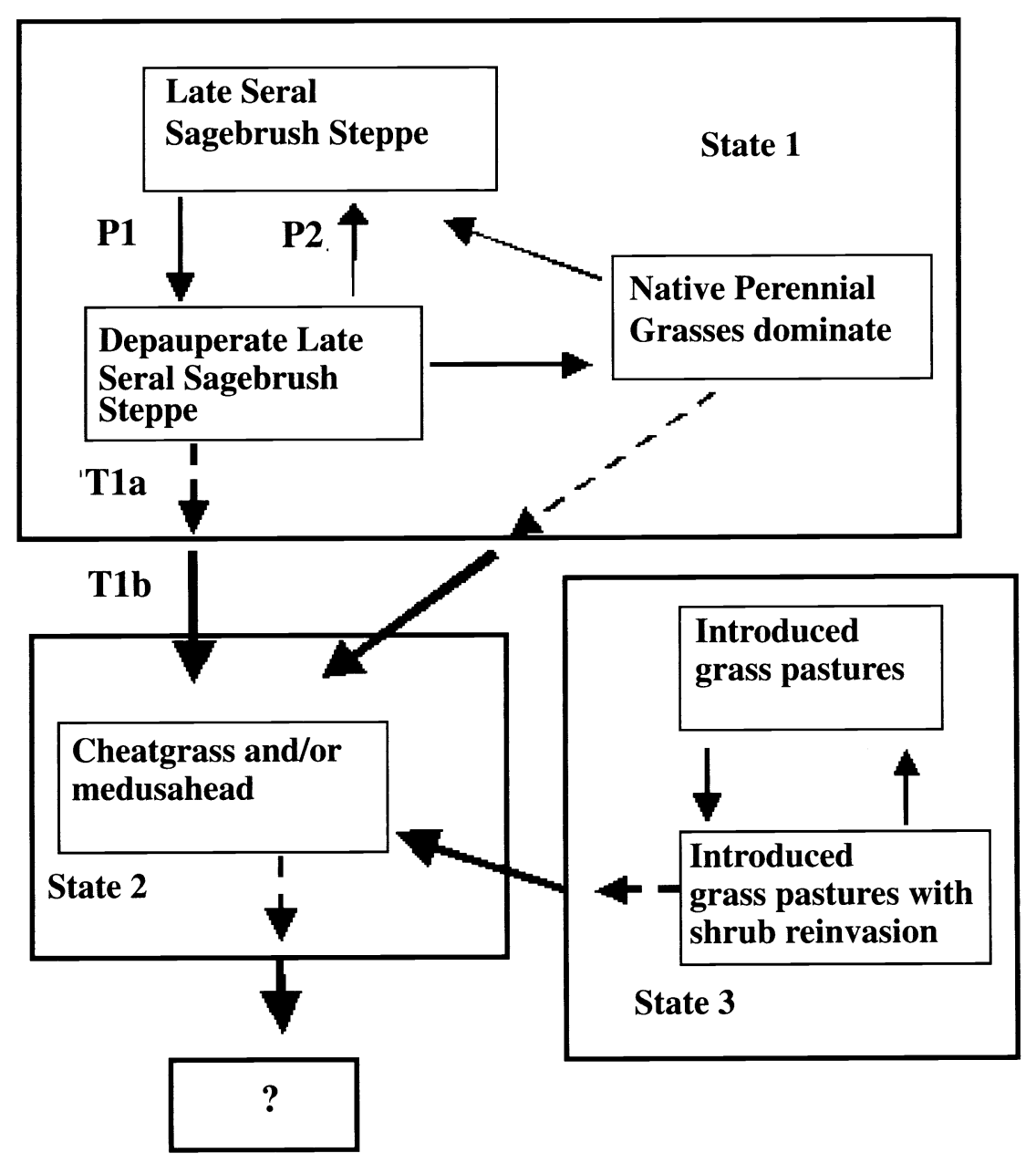

Fig. 5. Modification of the West (1999) and West and Young (2000) specific sagebrush steppe model (see Fig. 2) to illustrate the broad concept of state with plant community phases and community pathways (i.e., P1 and P2) within states. T1a and T1b signify the reversible and irreversible properties of the transition between State 1 and State 2. For additional discussion of the mechanisms leading to community phase shifts see West (1999) and West and Young (2000).

and concepts and to link them together into a process-based model for management and research. The management and natural mechanisms responsible for community phase shifts and transition initiation must be included in the model description. The description of these mechanisms should contain information on their impact on the primary ecological processes and the resulting change in the biotic community and system function. Further research is needed to identify indicators of change for ecological processes that will allow management to intervene prior to a threshold change. Once a threshold has been crossed, the focus of management should be on restoration of the damaged ecological processes, not on reestablishing a specific plant community. Although this conceptual model suggests
Anderson, J.E. 1986. Development and structure of sagebrush steppe plant communities. In: P.J. Joss, P.W. Lynch, and O.B. Williams (eds.) Rangelands: A resource under siege Proc. of $2^{\text {nd }}$ Internat. Rangeland Congress. Aust. Acad. of Sci., Canberra, Aust.

Archer, S. 1989. Have southern Texas savannas been converted to woodlands in recent history? The Amer. Natur. 134:545-561.

Archer, S. and F.E. Smeins. 1991. Ecosystem-level processes, p. 109-139. In: K. Rodney and Jeffery W. Stuth (eds.) Grazing Management an Ecological Perspective. Timber Press, Portland Ore.

Davenport, D.W., D.D. Breshears, B.P. Wilcox, and C.D. Allen. 1998. Viewpoint: Sustainability of pinon-juniper ecosystems a unifying perspective of soil erosion thresholds. J. Range Manage. 51:231-240.

Dyksterhuis, E.J. 1949. Condition and management of rangeland based on quantitative ecology. J. Range Manage. 2:104-115.

Foran, B.D., G. Bastin, and K.A. Shaw. 1986. Range assessment and monitoring in arid lands: the use of classification and ordination in range survey. J. Environ. Manage. 22: 67-84.

Friedel, M.H. 1991. Range condition assessment and the concept of thresholds: A viewpoint. J. Range Manage. 44(5):422-426.

Fuhlendorf, S. D., F. E. Smeins, and W. E. Grant. 1996. Simulation of a fire-sensitive ecological threshold: a case study of Ashe juniper on the Edwards Plateau of Texas, USA. Ecol. Modelling 90:245-255.

Holling, C. S. 1973. Resilience and stability of ecological systems. Ann. Review Ecol Systematics 4:1-23.

Iglesias, R.M.R. and M.K. Kothmann. 1997. Structure and causes of vegetation change in state and transition model applications. J. Range Manage. 50(4):399-408.

Laycock, W.A. 1991. Stable States and thresholds of range condition on North American rangelands: A viewpoint. J. Range Manage. 44(5):427-433.

Margalef, R. 1969. On certain unifying principles in ecology. Amer. Natur. 97:357-374.

May, R. M. 1977. Thresholds and breakpoints in ecosystems with a multiplicity of stable states. Nature 269:471-477.

Milton, S. J., W. R. J. Dean, M. A. duPlessis, and W. R. Siegfried. 1994. A conceptual model of arid rangeland degradation. Biosci. 44:70-76.

Noble, I. R. and R. O. Slatyer. 1980. The use of vital attributes to predict successional changes in plant communities subject to recurrent disturbances. Vegetatio 43:5-21.

Noy-Meir, I. and B.H. Walker. 1986 Stability and resilience in rangelands. p. 21-25. In: P.J. Joss, P.W. Lynch, and O.B. Williams. (eds.) Rangelands: a resource under siege - Proc. of the $2^{\text {nd }}$ Internat. Rangeland Congress. Australian Acad. of Sci.. Canberra, Aust.

Oliva, G., A. Cibils, P. Borrelli, and G. Humano. 1998. Stable states in relation to grazing in Patagonia: a 10-year experimental trial. J. Arid Environ. 40:113-131. 
Pellant, M. P. Shaver, D. A. Pyke, and J. E Herrick. 2000. Interpreting indicators of rangeland health, ver. 3 , Tech. Reference 1734-6. USDI, BLM, Nat. Sci. and Tech. Center, Denver, Colo

Petraitis, P.S. and R. E. Latham. 1999. The importance of scale in testing the origins of alternative community states. Ecol. 80(2): 429-442.

Plant R.E., M.P. Vayssieres, S.E. Greco, M.R. George, and T.E. Adams. 1999. A qualitative spacial model of hardwood rangeland state-and-transition dynamics. J. Range Manage. 52:51-59.

Rietkerk, M. and J. van de Koppel. 1997. Alternate stable states and threshold effects in semi-arid grazing systems. Oikos 79:69-76.

Smith, E.L. 1988. Successional concepts in relation to range condition assessment. $p$. 113-133. In: P.T. Tueller (ed.) Vegetation science applications for rangeland analysis and management. Kluwer Academic Publishers, Boston, Mass.

Society for Range Management, Task Group on Unity in Concepts and Terminology. 1995. New concepts for assessment of rangeland condition. J. Range Manage. 48:271-282.

Stringham, T.K. 1996. Application of nonequilibrium ecology to managed riparian ecosystems. Ph.D. Diss.. Dept. of Rangeland Resour., Oregon State Univ., Corvallis, Ore. pp.156.
Stringham, T.K., W.C. Krueger, and P.L. Shaver. 2001. States, transitions, and thresholds: Further refinement for rangeland applications. Agr. Exp. Station Special Rep. 1024. Oregon State Univ., Corvallis, Ore.

Tausch, R.J., P.E. Wigand, and J.W Burkhardt. 1993. Viewpoint: plant community thresholds, multiple steady states, and multiple successional pathways: legacy of the Quaternary? J. Range Manage. 46:439-47.

USDA, Natural Resources Conservation Service. 1997. National Range and Pasture Handb. : USDA. Washington D.C

Verhoff, F. H. and F. E. Smith. 1971 Theoretical analysis of a conserved nutrient ecosystem. J. Theor. Biol. 33:131-147.

Walker, B.H., D. Ludwig, C.S. Holling, and R.M. Peterman. 1981. Stability of semi-arid savannah grazing systems. Ecol. 69:473-498.

Weixelman, D.A., D.C. Zamudio, K.A. Zamudio, and R.J. Tausch. 1997. Classifying ecological types and evaluating site degradation. J. Range Manage. 50(3): 315-321.

West, N. E., 1979. Basic synecological relationships of sagebrush-dominated lands in the Great Basin and the Colorado Plateau. In Anon, The sagebrush ecosystem: A symposium. Utah State University, College of Natural Resources, Logan, Utah.
West, N. E. 1999. Managing for biodiversity of rangelands. p. 101-119. In: W. Collins, C. and Qualset (eds.) Biodiversity in Agroecosys-tems. CRC Press Washington, D.C

West, N. E. and J. A. Young. 2000. Intermountain valleys and lower mountain slopes p. 256-284 In: Barbour, M. G. and W. D. Billings (eds.) North American Terrestrial Vegetation, Second Edition. Cambridge Univ. Press, New York, N.Y.

Westoby, M. 1980. Elements of a theory of vegetation dynamics in rangelands. Israel $\mathrm{J}$. Bot. 28:169-194.

Westoby, M., B. Walker, and I. Noy-Meir. 1989. Opportunistic management for rangelands not at equilibrium. J. Range Manage. 42(4):266-274.

Whisenant, S. G. 1999. Repairing damaged wildlands: A process-oriented, landscapescale approach. Cambridge Univ. Press. 312 pp.

Wilson, A.D. 1984. What is range condition: development of concepts in Australia. Bull. Ecol. Soc. Amer. 65:171.

Wissel, C. 1984. A universal law of the characteristic return time near thresholds. Oecologia 65:101-107. 